\title{
XLIII.-Laboratory Notes.
}

Br H. endemann, Ph. D., and Geo. A. Prochazka, Ph. D.

I.-STANDARD SODA SOLUTION.

Gerresheim has published in the first volume of the "Annalen der Chemie," for the year 1879, an article on ammoniacal mercury compounds, wherein he calls attention to the pronounced basic properties of the so-called Millon's base, which is obtained by the action of ammonia upon mercuric oxide. He states that a soda solution to which hydrochloric and sulphuric acid, etc., have been added, can be freed from these by shaking with Millon's base. Mercury is not found in the solution. We have made use of this method in order to obtain a chemically pure standard soda solution from the ordinary so-called pure caustic soda, and have found all, which the author claims, verified. The soda contained large quantities of chlorine, sulphuric acid, and, also, silicic acid and carbonic acid. We employed for 2 liters soda solution about 30 grms of Millon's base. The chlorine disappeared first, then carbonic acid, silicic acid and sulphuric acid. 'The process was completed after about one week's standing, the mixture being shaken about once or twice each day.

We allow the Millon's base to settle in the solution, and draw off with a syphon as required. Shaking from time to time removes any carbonic acid which may be absorbed by the soda in the course of time. Millon's base absorbs carbonic acid from the air rapidly, and is, also, not easily filtered and washed. It was, therefore, not completely washed free from the last traces of ammonia, as we preferred to remove these by the addition of a small quantity of mercuric oxide when the Millon's base was brought into the soda solution.

\section{II.-HYDROBROMIC ACID AS A VERY DELICATE TEST FOR COPPER.}

A solution of cupric bromide is blue; if the same is evaporated, the solution turns, at first, dark, reddish-lrown, leaving finally the anhydrous bromide as an almost black mass.

The dehydration can, also, be produced by the addition of a concentrated solution of hydrobromic acid; if, therefore, to a dilute solution of a copper salt concentrated hydrobromic acid is added, a dark, brownish-red or violet color, is at once produced.

This reaction is so delicate that roo mgrin of copper can be detected with certainty. One drop of a solution containing this small quantity of copper is brought on a watch glass, then one drop 
of hydrobromic acil is added, and the solution is then allowed to evaporate slowly by standing the glass on a warm place. When the whole has been concentrated to about one drop, this will distinctly show a rose-red color. The color thus produced is about is to 4 times as distinct as the one which is obtained by the addition of ferrocyanide of potassium. of other metals which are examined in this direction, we find only iron to be apt to interfere with this reaction, and then only when it is present in (onsiderable quantity.

We think that this reaction may also be atilized as a colorimetric test for the quantitative detcrmination of small quantities of copper.

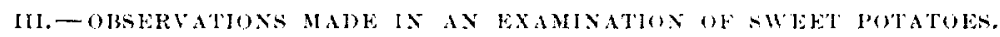

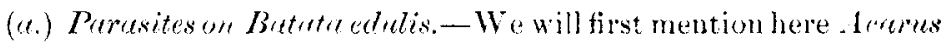
saccheri, the sugar mite, which is commonly found in raw sugars. A

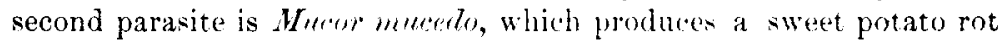
very similar to that produced by perenospera on the ordinary potato.

The mycelium of Minom inemede travels soon into the interiol. plant, and can be followed with the microscope to a certain depth; it then, however, disippears, and from that point on the potato is rapinly destroyed by bacteria. An infoction by either. Mucor menedo, or the bacteria, is equally effecteve in destroying the potato, which soon becomes soft throughout.

A similial, but by far not so rapid, result is reached, if the infection is produced by Aspergillus wiger. Aspergillus glancus and Penirillinire gluerens do not produce the sweet potato rot. The question whether Mucor musedo has nerely been effective in preparing the ground for a bealthy development of the bacteria, or whether these organisms are merely a lower organized shape of Mucor mucedo, we will not decide, but must leave this to the study of botanists.

$\Lambda$ peculiar odor produced during this fermentation, bears great resemblance to the odor of rose geranium.

(b.) Chemicul excunination.-In making this, it was our endeavor to obtain a certain substance, presumably a glueoside, in larger quantities. This we obtained, but not in such purity as we desired. A certain quantity of fat has adhered to it all along, and our efforts to find a method of separation bave thus far been in vain.

The sugar of the sweet potato has never been designated-most authors calling it simply sugar, without going into details. Ledoux, in his last report on the work of the experimental station at Chapel Hill, N. C., calls the sugar, glucose. We will state, therefore, that we have obtained this sugar in crystals, which, to all appearances, are cane sugar. 